\title{
Variation in English syntax: theoretical implications ${ }^{1}$
}

\author{
DAVID ADGER \\ Queen Mary, University of London \\ and \\ GRAEME TROUSDALE \\ University of Edinburgh \\ (Received 26 September 2006; revised 19 February 2007)
}

\begin{abstract}
This article provides an overview of the relationship between studies of syntactic variation in dialects of English and theoretical accounts of language structure. In the first section of the article, we provide a discussion of the place of syntactic variation within various subdisciplines of linguistic enquiry: we address issues such as I- and E-language, the place of Standard English in linguistic theory, and interfaces between traditional dialectology, variationist sociolinguistics, and theoretical linguistics. These interfaces suggest the need for a clarification of the nature and status of the (morpho)syntactic variable, which we provide in section 3; and in section 4, we examine the way in which (morpho)syntactic variation is treated within a number of theoretical models - for instance, Principles and Parameters theory, HPSG, OT, and cognitive linguistics (including Word Grammar and Construction Grammar) - all of which feature in the other articles in this special issue.
\end{abstract}

\section{Introduction}

Varieties other than the standard have been the main source of data on which many key concepts in dialectology and variationist sociolinguistics have been built. However, within theoretical linguistics, the analysis of nonstandard varieties of English particularly the analysis of morphosyntactic and syntactic variation in English - has, until fairly recently, been less conspicuous. Yet the modelling of (syntactic) variation in and across dialects is a critical issue in any theoretical framework, as variation is ubiquitous in language, and the fact that language can vary raises important questions regarding what the theory is actually modelling.

Many factors have contributed to this neglect. First, following much work in the descriptive grammar of English, theoreticians have, for the most part, constructed their theories as models of Standard (American) English, with occasional asides to the fact that things work differently in other varieties. The assumption that underlies this is that there is in fact little theoretically significant variation in English as a whole: for example, wh-questions, raising and control constructions, passives, basic clausal structure, etc. appear to be fairly stable across varieties, and it is these (and similar) phenomena that, at heart, form the core data for the construction of the theory. It is indeed true that vast realms of English syntax vary little, and that these areas are especially useful when

${ }^{1}$ We are grateful to Jenny Cheshire, Bernd Kortmann, Laura Rupp, and Jennifer Smith for their comments on previous versions of this article. 
looking for syntactic principles, but, as is evident from the other articles in this special issue, variation does occur and it is highly significant for the development of theories of language. A second, but related, reason for the neglect is the tacit assumption that Standard English is a reasonable object of study, in that it idealizes the particular languages of different speakers (see below in section 2.1 for critical discussion of this assumption). Following Chomsky's (1965) argument that it is legitimate to idealize the object of study in linguistic theory, researchers have tended to ignore variation that challenges this idealization. Finally, work on Standard English (i.e. the educated English of many of the researchers) is simply much easier than work on dialectal varieties, as the researcher can simply use his or her own intuitions about well-formedness, appropriateness to context, ambiguity, etc. This saves much time and energy on the part of the researcher, and obviates the need for fieldwork and for dealing with the complications that arise in collecting dialectal data. Moreover, as noted above, the researcher can still make important contributions to theory without appeal to dialectal data.

Within the dominant Chomskyan framework of the early 1980s, primary attention to linguistic varieties was at the macroparametric level, but an increasing number of syntacticians have become concerned with microparametric variation within a range of different languages (e.g. Black \& Motapanyane, 1996; Cornips \& Corrigan, 2005; Henry, 1995). This work was not without precedent (see, for example, Carden, 1973; Kimball \& Aissen, 1971), but it came into theoretical focus in the 1990s. Such an interest in dialect syntax has not been restricted to transformational generative grammar: we also find such work within constraint-based approaches to grammar such as Head-driven Phrase Structure Grammar (HPSG) and Lexical Functional Grammar (LFG) (Bender, 2001; Bresnan, 2000) as well as in Construction Grammar (for instance, Leino \& Östman, 2005), while Bhatt (2000) provides an Optimality Theoretic (OT) account of certain aspects of grammatical variation within Indian English. This article (and indeed this special issue as a whole) builds on this research and discusses some of the critical issues in English dialect syntax which are of relevance primarily to theoretical linguists, but also to those working within traditional dialectology and variationist sociolinguists, because we believe that there are a number of interfaces between these disciplines which can usefully be explored.

The structure of the article is as follows: section 2 is concerned with the place of syntactic variation within various subdisciplines of linguistic enquiry; section 3 investigates the nature and status of the (morpho)syntactic variable; and section 4 explores the way in which (morpho)syntactic variation is treated within a number of theoretical models, many of which feature in the other articles in this special issue.

\section{The research context}

\subsection{What varies?}

When we ask questions about language variation, we must first ask what we mean by 'language'. Chomsky (1986) discusses two perspectives one can take on language, 
which he terms the E-language perspective and the I-language perspective. The former conceives of language as a set (or system) of external forms paired with meanings, and so sees the study of language as the study of this set/system: essentially one takes a corpus of utterances as the object of empirical study, and the theoretical questions that arise are about the range of grammars which can characterize this corpus. From this perspective, as Quine (1960) noted, there is no 'correct grammar', the theoretician is free to choose whichever grammar correctly captures the system, and there may be a multiplicity of these. Note that this perspective allows us to study language independently of the minds that produce the linguistic system: all we need is a theory of the system itself. The E-language perspective is essentially a characterization of the kinds of philosophically externalist views of language espoused by Quine and others.

An alternative is to see language as something internal to the mind of the speaker, which is used by the speaker to produce utterances and other linguistic forms. This is the I-language perspective, and it sees language as part of the biology of human beings. In the same way that the physical body of any particular human is the product of that individual's genetic heritage and the individual's own life experiences (nutrition, exposure to sunlight, etc.), so the language of an individual is a function of some genetic specification and some environmental (linguistic) input. From this viewpoint a theory of (I-)language is a theory of an ultimately biological property of human beings, the faculty of language. It follows that, in contrast to what we just concluded for E-language, there is a fact of the matter, much as there is in physical, chemical or biological investigations. Our theories, of course, are not correct and complete accounts of the facts, but we assume there are facts and our theories allow us some understanding of these.

This I-language approach is the one taken in (Chomskyan) Generative Grammar, and it takes human language to be a property of the natural world, and therefore susceptible to experimental study, but also to observational study. Much work so far in Generative Grammar has taken experimental study (and its manifestation as informant judgement tasks) as the primary methodology, but it is important to realize that nothing in the underlying theory precludes observational approaches (which of course are used in other naturalistic investigations, such as environmental change, astronomy, etc. and are seen as complementary to experimental work, rather than being in conflict with it).

A different perspective on language from the E-/I-language approach, which does give primacy to observational methods, is taken in the writings of Labov (1972). Labov takes the aim of linguistic investigation to be to uncover patterns, not at the level of the individual, but rather at the level of the speech community (see e.g. Labov, 1989). The reason for this is his claim that there are generalizations about linguistic patternings that can only be discovered by looking at the whole community. The patternings that Labov is talking about are statistical patterns in the use of different variants. From this perspective, the object of study and the primary focus of interest is not something in the mind of the individual, nor is it a set of form-meaning pairs: it is a property of a community of individuals. This perspective (which Adger \& Smith, in preparation, call an S-language approach) leads fairly naturally to an observational methodology. Since 
this perspective is interested in patterns of use across communities, the methodology adopted has to be one which allows (and, in fact, necessitates) gathering data about language use from observations of the linguistic behaviour of a number of individuals in the community. The methodology developed by Labov and his colleagues has, then, been a mainly observational one, which has perforce had to use statistical techniques in the subsequent analysis to uncover the patterns of use.

The E-language approach to linguistics has found little favour amongst theoretical linguists (although see e.g. Katz, 1981 for a dissenting voice); most have taken an I-language approach and, because an informant-judgement-based methodology is relatively unproblematic for many phenomena, have concentrated on building theories using data from informant judgements. However, this has almost certainly led to a reduction in the range of variation that is found, because of the impact of standardization on speaker judgements (see below). One means of overcoming this is, of course, to adopt the observational methods developed by Labov in conjunction with informantbased methods (as was recommended by Labov, 1972). Adoption of such methods does not, however, require one to adopt an S-language viewpoint, although it does raise questions about what variation across individuals can tell us about I-languages per se. For instance, are the generalizations found by looking at communities always able to be down-scaled to the individual level in cases where there may not be enough data (see Guy, 1980 for discussion)? As mentioned above, both experimental and observational methods are valid approaches to natural phenomena, which is what the I-language perspective takes language to be.

When one takes such an observational approach, one is immediately faced with a fair amount of variation that has to be accounted for within a theoretical framework. Empirical studies have shown over and over again that individuals within speech communities display variation in their grammatical repertoire. For example, as discussed by many of the papers in Cornips \& Corrigan (2005), agreement and word order can vary in a way that is not plausibly tied to semantics or information structure. This means that not only is there geographical variation between speakers leading to dialect differences, but that the grammar of individual speakers is itself variable. What is interesting about this outcome is that it engenders a tension with certain explanatory models in theoretical linguistics. Over the past decade, Chomsky has been arguing for the idea that I-language is in certain respects optimal and that it lacks optional operations. Variation in form, without corresponding variation in meaning, seems to be a case of optionality, and this raises a challenge for at least this version of current linguistic theory (see Adger, 2006 for one response to this challenge).

\section{2 'Standard English' in linguistic theory}

In both formal accounts of syntactic variation and traditional sociolinguistic accounts of variation, the notion of the standard variety has been influential, but often ill-defined. Partly this is a result of two contrasting ways of approaching what constitutes the 
standard variety within sociolinguistic theory. ${ }^{2}$ One approach is to consider the standard as a variety of English like any other, one which is spoken (at least on occasion) and written by a group of speakers; corpora of Standard English are therefore available for collection and analysis, and can legitimately be compared and contrasted with corpora of nonstandard varieties. The contrasting approach considers the standard as an ideology (cf. Milroy \& Milroy, 1991), a set of beliefs shared to varying degrees by speakers and writers of English, inculcated in the classroom and disseminated through parts of the media. Problems associated with the characterization of 'Standard English', therefore, are not connected merely to the delineation of varieties of English (cf. Hudson, 1996), but also to the ideology of the standard. It is clear that Standard English is essentially a social object and not a natural one and this fact impacts in the informant judgement methodology of much of theoretical linguistics.

Any particular individual's grammaticality judgements are dependent on a host of factors: one very important one is that person's I-language, which, in the case of dialect speakers, may be quite distinct from the Standard English version of the language in phonology, lexis, morphology and syntax. However, for many people, there is also a great deal of knowledge about the 'Standard'. This knowledge of the 'Standard' is the product of a series of educational and social factors which have overtly impinged on the linguistic experiences of individuals, prescribing the correctness/incorrectness of certain constructions. Many of those individuals who acquire Standard English acquire it much later than their native variety, and informant judgements about Standard English do not necessarily reflect the individual's I-language: they may be judgements which are informed by explicit teaching or implicit reinforcement of norms.

For example, the native variety of one of the authors of this piece (David Adger) has quite a different system in the syntax of negation from Standard (British) English: ${ }^{3}$ this system involves negative concord, including negative concord with negative VPs when negation is contracted to certain modals:

(1) He canny go. $=$ He can't go.

(2) He canny no be there. $=$ He can't be there.

This is not a pan-Scottish phenomenon (it is not, for example, found in the north of the country). Even though Adger's English, as he now speaks it, seems like a very standard version of Scottish English, with a fairly anglicised phonology and syntax, his judgements about relative scopes of negation and modals are actually rather confused. What then is the status of Adger's judgements about a Standard English sentence like (3)?

(3) He can't not be there.

At the very least, one might be suspicious of any such judgement. Generalizing this case, it seems clear that Standard English cannot be taken as a reasonable idealization,

\footnotetext{
2 We are grateful to Jenny Cheshire for drawing our attention to this contrast.

${ }^{3}$ For further discussion of negation in nonstandard varieties of British English, see Anderwald (2002).
} 
and we suggest that the assumption that it is always a good data source for theories of I-language is no longer reasonable, given the complexity of the kinds of questions that syntacticians are now asking.

This brings us back to the point we made earlier, that it is important to use both experimental and observational methods: as we have just discussed, informant judgement tasks involving dialect speakers, as usually carried out, may lead to skewed results, because of the speaker's conscious knowledge of the standard variety. This is true even for speakers of dialect varieties who have not altered their speech patterns to conform to an educated standard. Given their schooling, and the impact of the standard variety in the spoken and written media, these speakers are often aware of the requirements of the standard language, and so their sociolinguistic knowledge impacts upon their judgements. This means that in looking at dialect syntax we must consider not just experimental methods using informant judgements, but also observational methods, which give us information about unreflecting speech patterns. Of course, such observational methods bring their own problems, not least questions of sufficiency of syntactic data and the difficulty of knowing why some form does not appear in a corpus (is it rare, or impossible?).

A separate issue is that the tradition of introspection in theory building is one which takes the researcher's own variety - usually together with an assumption that this variety is close to the 'standard' - as the data source for the construction of a particular argument. This marginalizes nonstandard varieties, despite the rich data which they provide. As other contributions in this issue clearly indicate, nonstandard dialects help to build theories of syntax. Such data are critical, given that consistent and total agreement on grammaticality among speakers of the same language is rare to the point of nonexistence: Kayne (1996: xv) raises important questions for syntacticians, dialectologists, and sociolinguists when he asks: 'can anyone think of another person with whom they agree $100 \%$ of the time on syntactic judgements (even counting only sharp disagreements)? Or more precisely, are there any two people who have exactly the same syntactic judgements without exception?' Indeed, Kayne's suggestion that no two speakers of English actually share the same grammar, and that even small differences in acceptability and judgement matter, are of direct relevance to the debate concerning individual and community grammars (see further section 2.3 below).

\subsection{Syntactic variation in English dialectology and sociolinguistics}

Syntactic variation in English dialects has been a thorny issue for dialectologists, sociolinguists, and theoretical linguists alike. Traditional dialectology had until recently a tendency to shy away from analyses of syntactic variation. For traditional dialectologists, the methods employed in collecting the data typically meant that very little material of use to those interested in syntactic variation was collected. For instance, the 'questionnaire' material for the Survey of English Dialects (SED; Orton, 1962) was designed to elicit only a minimal number of responses providing data for syntactic analysis, and although the incidental material provided some further material 
(cf. Upton et al., 1994), the amount of usable data is only a fraction of what is available for researchers interested in phonological variation in English dialects. This underscores the point that grammatical variation was not of primary concern to the $S E D$ compilers, and is a consequence of the research design: the objectives of the $S E D$ were primarily to investigate the reflexes of historical phonological changes as they were manifest in contemporary dialects (cf. Kretzschmar, 1999), so it is not surprising that little in the way of syntactic material was collected.

Furthermore, practical issues of method are often cited as a reason for the avoidance of engaging with grammatical variation. For example, while phonetic variables are common, certain morphosyntactic ones are rare (Chambers \& Trudgill, 1991; Milroy, 1987; Miller \& Cann, 1994). Moreover, some variants within a variable context are also very rare (for example, the for to variant in nonfinite complement clauses, or double modals, Trousdale, 2003a), which creates further difficulties in establishing correlations. However, quantitative studies of variation in inflectional paradigms (see almost any issue of the journal Language Variation and Change) have shown that some morphosyntactic variables appear frequently in naturally occurring speech. This has meant that some morphosyntactic variables have been sufficiently frequent in discourse to allow them to be correlated with sociolinguistic and stylistic variables (with concomitant statistical testing), which in turn has led to the claim that morphosyntactic variation typically stratifies social groups - particularly social classes - sharply, as opposed to the more fine-grained distinctions which emerge from studies of phonetic and phonological variation (Chambers, 2003).

The advent of variationist sociolinguistics brought with it a new set of problems, while retaining some of those outlined above in relation to traditional dialectology. Much of the early work within the quantitative paradigm continued to be concerned primarily with phonological variation and change, though there are notable exceptions (e.g. Cheshire, 1982). Both theoretical and practical issues regarding the syntactic variable emerged: Lavandera (1978) and Cheshire (1987) illustrated ways in which the syntactic variable was ontologically different from the standard conception of the sociolinguistic variable (which was conceived primarily with phonetic and phonological research in mind). This is discussed in greater detail in section 3 below. Some of the problems inherent in the treatment of syntactic variation are methodological: our understanding of the nature of the (morpho)syntactic variable is dependent on the nature of the data in which the variants appear, and fieldwork methodology. Sociolinguistic and stylistic correlations are influenced by the manner in which the data are collected. Elicitation tests can provide a way of investigating less frequently occurring morphosyntactic variables, but such a method cannot place the syntactic variation within its wider discourse context. It has been suggested that narrative within the formal sociolinguistic interview comes closest to representing natural speech, within which speech event the informant uses syntactic patterns which come closest to his or her everyday style. But true conversational narrative is by definition precluded from the interview, since the conversational narrative relates to and springs from whatever topic is being discussed, and a question-and-answer session prevents (or 
at least hinders) the informant from introducing discussion topics of his or her own choosing. Attempts to circumvent this obstacle, by suggesting topics to the informant (cf. the infamous danger of death question in Labov, 1966), do not solve the problem, since such a narrative is in essence an extended response (Wolfson, 1976), and therefore different from traditional narrative. Whatever methods of data collection are adopted, they have a bearing on our understanding of what it is that a speaker knows when he or she exploits morphosyntactic variation.

More general issues of sociolinguistic theory are also relevant to the study of syntactic variation. Debates within variationist sociolinguistics - concerning, for example, the status of the speech community (Patrick, 2002), and the emergence of social network analysis and communities of practice (Milroy, 2002; Meyerhoff, 2002) - have also had an impact on how dialect syntax should be analysed. A framework which aligns grammars with speech communities rather than individuals (e.g. Labov, 1989) requires a different approach to the study of syntactic variation than one which considers community grammars to be impossible to define (e.g. Hudson, 1996). Both such approaches take dialect syntax seriously, but claim to model very different things. This is of relevance not only for the analysis of synchronic variation, but also for language change. An individual's acquisition of a different or variable grammatical structure - a resetting of a particular parameter, a novel form-meaning construction, or the reranking of a constraint, for instance - takes place within the context of language use (in both perception and production). Language use is therefore important for all theoretical modelling of linguistic variation and change.

\section{3 (Morpho)syntactic variation and change}

\subsection{What is a (morpho)syntactic variable?}

Descriptions of grammatical variation in present-day English dialects such as Kortmann \& Schneider (2004) and Kortmann et al. (2005) illustrate the wide range of syntactic differences which speakers of nonstandard varieties exploit. Most of the variables described are morphosyntactic, and are concerned with variation in functional categories such as tense, modality, and negation, though some are syntactic (e.g. word-order patterns in embedded and nonembedded questions). The existence of such variation raises questions for the definition of the (morpho)syntactic variable - hereafter MSV - and its application to the sociolinguistics of dialect syntax.

From a certain perspective, the MSV is merely a subcategory of general linguistic variables. Adger (2006) suggests that one view of morphosyntactic variants sees them as akin to allophones/allomorphs: there is an abstract underlying unit which has a range of exponents. He terms this Variation in Exponence (VE). On this interpretation, the variable is no different from a phoneme or morpheme. What distinguishes the variable from the phoneme/morpheme is that its variants are not simply determined by the linguistic context in which they appear, nor are they simply in free variation. Rather they are more or less likely to be selected depending on the previous discourse, the 
speaker, the audience, and other psycholinguistic and sociolinguistic factors. In other words, the VE of variables is not only formal, but functional; not restricted to linguistic representation, but related to language in use (cf. Szmrecsanyi, 2006).

Adger suggests that variation can arise in another fashion as well though: it can arise also from 'the combinatorics of the syntactic system itself' (2006: 511), with the variants depending on what are essentially different syntactic routes to the same outcome. In a similar vein to Anttila's or Guy's work on phonology (Anttila, 1997; Guy, 1991), Adger argues that the combinatorics of the system can impact on the frequency of the variants. However, even in such systems, matters of online production and interaction (such as ease of lexical access or choice of words appropriate to the interlocutor) will still impact on the probability of particular lexical choices in particular situations.

While such practices work well for the MSVs ${ }^{4}$ that can be straightforwardly tied to the choice of particular lexical or grammatical forms, the situation with syntactic variables (SVs) - for example, word-order variation - is more problematic. Jacobson (1980: 23-4) has argued that syntactic variants should:

(a) be descriptively synonymous

(b) belong to the same semantic field

(c) be functionally comparable

(d) be structurally comparable

Such criteria illustrate the interface between SVs and discourse phenomena. The issues here arise in a sharp form when we take different constructions as variants: for example, should active and passive be seen as variants of each other (cf. Weiner \& Labov, 1983)? In early transformational grammar, active and passive were indeed seen as variants of the same underlying form. The base systems generated a 'kernel' sentence, and then a sequence of transformations could be applied to this. As these transformations did not change meaning, and as meaning was read off the 'kernel', we have two variants of a single underlying form. The early variable rules paradigm developed by Labov adopted an architecture related to the one just described, leading to the question of whether active and passive could be dealt with in the same way as other linguistic variables (Lavandera, 1978; Cheshire, 1982; Romaine, 1982).

However, as generative grammar developed, semantic interpretation was eventually concluded to be read off the output of transformations, rather than the input. This means that the semantic component interprets the structures provided by an autonomous syntax. Given this, the semantic component can be sensitive to the different structures provided by the grammar, and it becomes a moot question as to whether two structures

\footnotetext{
${ }^{4}$ Lavandera (1978: 175) argues that 'units beyond phonology, let us say a morpheme, or a lexical item, or a syntactic construction, each have by definition a meaning. They are not like phonenes [sic] which, by definition, do not have any "constancy of reference".' Such an analysis, however, presupposes a particular theory of grammar. While syntactic variables such as the agentless passive may well lack constancy of reference, the position with morphosyntactic variables is less clear, and certainly open to debate within and between different frameworks, as we argue immediately below.
} 
have the same meaning: this is no longer a given, but something which is 'up for grabs'. In addition, syntactic arguments led to the viewpoint that active and passive do not share the same underlying form: they have different forms and their similarity in meaning is captured by the operation of the semantic component interpreting structure. All of this means that it is difficult to take active and passive to be variants in the way we defined them above: two outward forms of a single underlying structure.

A further issue arises from the interplay between (variationist) sociolinguistics and linguistic theory. In his discussion of the Hiberno-English tense-aspect system, Harris (1984) considers the issue of structural identity in standard and nonstandard grammars, and argues that a traditional sociolinguistic approach to the relationship between standard and nonstandard syntactic variants can tend to be overly reductive, to create 'the impression that differences between the standard and a particular vernacular are merely superficial and ... to obscure what deep-seated divergences there might exist between the two varieties' (Harris, 1984: 304). This too relates to issues in the definition of the SV noted above. For some (e.g. Jacobson, 1980), criteria for a syntactic variant rely in part on semantic equivalence; Harris argues that such equivalence is only relevant if dialect variants are seen to be differing surface realizations of the same deep structure. Therefore, a syntactic variant arising from differences within a dialect is not necessarily of the same type as one which arises from differences between two dialects, such as the different interpretations of How long are you here? in Standard English and Hiberno-English. In other words, inter- and intradialect variation depends on whether separate dialects are shown to have different grammatical subsystems.

\subsection{English dialect syntax and language change}

The alleged conservative nature of nonstandard dialects has been questioned by some recent investigations into varieties of English: Trousdale (2003a, b) illustrates that, in some respects, the modal system of speakers of Tyneside English is more conservative than that reported for speakers of the British standard variety (e.g. in the use of double or multiple modals), while in other respects it is more innovative (e.g. in the avoidance of may as a marker of both epistemic possibility and deontic necessity); for further examples, on a global scale, see Kortmann (2006: 615-16). Trousdale (2003b) also notes that the modal system of Tyneside English displays patterns associated with (dialect) levelling (cf. Kerswill, 2002), and this tendency towards greater regularity is characteristic of a range of features of English dialects, such as the use of ain't for all persons in the paradigms of auxiliary have and be, and main verb be (Cheshire, 1982), syncretism between past tense and past participle forms of strong verbs, and the persistence of $d o$-periphrasis in nonemphatic positive declaratives (Ihalainen, 1991). While most of the articles in the present issue are concerned with synchronic variation in English dialects, the relevance of dialect syntax patterns within English historical linguistics should also be borne in mind. Work on morphosyntactic variation and change in the early Modern English period, using the Corpus of Early English Correspondence (see Nevalainen \& Raumolin-Brunberg, 2003), has illustrated some of the ways in 
which regional and social factors have correlated with quantitative distributions of linguistic forms. Such factors include geographical and social mobility in relation to the diffusion of northern English variants into the language of the emergent southern middle class. The data also provide sociolinguistic evidence for changes to the English auxiliary system, particularly the emergence of $d o$-support, a topic which has attracted attention from linguists of quite different theoretical persuasions (e.g. Kroch, 1994; Hudson, 1997). While the notion of the linguistic variable has from its inception been influential for an understanding of phonological change, the extension of the concept to morphosyntactic change within the domain of historical linguistics generally, and changes in the syntax of varieties of English in particular, has engendered both descriptive and theoretical advances.

\section{Theoretical accounts of syntactic variation in English}

\subsection{Formal approaches}

From an I-language perspective there is, of course, no naturalistic notion that corresponds to our usual use of the words 'dialect' or 'language'. There are individuals who have I-languages, and those I-languages are the product of (probably speciesuniversal and species-specific) genetic endowment and individual experience. The reason why people who live closely together can understand each other is because they share a genetic endowment (by virtue of being human) and common (linguistic) experience. However, as we noted above, following Kayne, everyone's experience is slightly different, and so we expect to see very small variations between the I-languages of people who, in commonsense terms, speak the same dialect. When communities of individuals end up having diverging histories, the differences between the I-languages spoken by their members have a tendency to also diverge, leading to what we commonly call dialects, with the familiar dialect-continuum effects when the impact of history and geography is considered (see Adger \& Ramchand, 2006 for discussion of how this model applies to variation in relative-clause formation across dialects of Scottish Gaelic). Given the I-language viewpoint, then, the theoretical mechanisms used to capture differences between languages should be identical to those which capture the differences between dialects and idiolects.

For example, if we look at Government and Binding Theory, the assumption is that there are fairly abstract general principles which are obeyed by all languages. However, some of these principles are parameterized: for example, all languages have a VP constituent which has the object as the sister of the verb, but in English the object sits to the right of the verb, while in Japanese the object sits to the left. This parameterization (Head-Right vs Head-Left) also holds for prepositions and nouns with their complement. In this approach, a language ends up being a specification of the parametric choices in the principles. Parameters can be conceived of as a set of binary switches, which can be set to on or off, and a language is simply a specification of the state of these switches. 
What this means at dialectal level is that dialects too differ in parametric choices. A good example of such work is Alison Henry's study of Belfast English (Henry, 1995). Henry shows that there is a fair amount of variation in Belfast English, and for certain constructions she argues that this can be modelled by having different parametric settings within a single dialect. More recently, Henry has emphasized Kayne's point, that even speakers of a single dialect may have quite different parameter settings leading to fairly radical intradialectal variation (see Henry, 1995, Henry \& Cottell this issue).

More recent work has taken parameters to just be lexical items. This idea stemmed from Borer (1984), which proposed that parameters were restricted to properties of the (functional) lexicon. This opens up a different conception of parameterization: rather than having a bank of switches, languages differ in that they have different specifications for certain lexical items. This doesn't seem like a major change; however, while it is impossible to have a switch being in both positions at once, it is certainly possible to have two lexical items in a language with contradictory specification. This idea has been exploited in recent work as a means of capturing variation within an I-language, as well as variation across the closely connected I-languages that constitute a dialect (see e.g. Adger \& Smith, 2005; Adger, 2006; Parrott, 2006).

Within HPSG the lexicon has also been seen as the repository of variation, although recent developments in HPSG have blurred the distinction between the lexicon and syntactic constructions. Bender (2001), formalizing a construction-based approach within HPSG, argues for attaching social meanings to constructions (see also Bender, this issue). A radically different approach to modelling variation is taken in Optimality Theory (OT). Within OT, a final structure is chosen as the grammatical structure if it optimally satisfies a set of constraints. OT treats variation between languages as arising from different rankings of these constraints. The constraints themselves are assumed to be universal. Obviously, optimal satisfaction of a set of constraints will tend to lead to a single outcome, and so to no variation. To deal with this, some OT theorists (e.g. Pesetsky, 1998) have suggested that the ranking of constraints is only partial (so for two given inputs, the output may not be determined). An alternative model involves allowing constraints to rerank in a slightly different way each time they are applied to an input (e.g. Nagy \& Reynolds, 1997), so that different outputs will result on different occasions. Finally, a yet more recent approach within OT involves placing the constraints on a scale of real numbers, and then adding different numbers from a normal distribution to each of these constraints, causing probabilistic effects in the resulting reranking (see Bresnan, Deo \& Sharma, this issue).

\subsection{English dialect syntax and cognitive linguistics}

There have, to our knowledge, been fewer detailed studies of syntactic variation in English within a cognitive linguistics framework than within other theoretical models. There are some discussions of the place of variability generally within cognitive frameworks such as Word Grammar (Hudson, 1986, 1997), and of phonological variation within the Cognitive Grammar framework (Casillas-Martinez, 2003; Mompean-Gonzalez, 2004). 
Furthermore, language-internal typological issues are of relevance, though as Kortmann (2006: 620) observes, functional typological accounts of dialect syntax are also less numerous, and therefore less well developed, than the microparametric studies of variation carried out within the generative tradition, some of which we outlined above. In this section, we show how some of the findings of studies into syntactic variation in English might be analysed within a broadly cognitive framework.

Usage-based models of language - such as Langacker $(1987,2000)$ and Croft (2000) - suggest that linguistic structure is not static but dynamic, acquired ${ }^{5}$ as a result of constant exposure to different usage events through time. Repeated exposure to the same set of forms leads to those forms being entrenched in the speaker's symbolic inventory; but the fact that such usage events are not always identical but variable means that the speaker must also abstract away from the events to create a set of schemas which sanction (either wholly or partly) the instances to which the speaker is exposed. ${ }^{6}$ Such a process of abstraction relies on an innate ability to categorize, and it is these processes which constitute a speaker's grammar: 'grammar is the cognitive organization of experience with language' (Bybee, 2006: 730). Variation is therefore at the heart of usage-based models of language, but not all usage-based models have a fully articulated account of how to model dialect syntax. Word Grammar (Hudson, 1990, 1996, 2007, this issue) has possibly the most systematic treatment of syntactic variation of all usage-based models: its network architecture and prototype-based means of classification (at all levels of the grammar) allow parallels to be drawn with categorization models in social psychology. Particularly, the network features of linguistic structure in Hudson's model and Milroy's social network analysis (Milroy, 2002) show some considerable overlap, especially if one treats the social network as a mental construct, a speaker's mind map of the social relations which exist between individuals (Clark, 2005). The correlation and quantification of linguistic variation and network strength in Word Grammar provides a good illustration of the way in which sociolinguistics and cognitive linguistics can be synthesized.

Dialect syntax is also increasingly prominent within construction grammars of various kinds (see Hollmann \& Siewierska, this issue; Leino \& Östman, 2005). For instance, research into the behaviour of collexemes in into-causative constructions (of the kind he swindled me into buying this car) in corpora of American and British English has illustrated that constructional and collostructional variation may have a diatopic correlation (Wulff, Stefanowitsch \& Gries, 2007).

Furthermore, certain principles of Construction Grammar raise interesting questions about the nature of syntactic variation, and the definition of the MSV. The Principle of No Synonymy, namely that 'if two constructions are syntactically distinct, they must be semantically or pragmatically distinct' (Goldberg, 1995: 67), must, following basic principles of construction grammars, apply to constructions at all levels of schematicity

\footnotetext{
5 We do not address specific issues of child language acquisition here: see Tomasello (2000) for a discussion of usage-based models of language acquisition.

${ }^{6}$ For further discussion of the relationship between entrenchment and syntactic variation, see Pietsch (2005).
} 
(i.e. from less schematic constructions such as the load/spray alternations to more schematic active/passive alternations); clearly intrapersonal variation constitutes a challenge to this idea (see Adger \& Smith, in preparation, chapter 1). Work on dialect variation within a general constructional approach to meaning creation is likely to yield results of considerable interest to dialectologists, typologists, and theoretical linguists alike.

\section{Conclusions}

Furthering our knowledge of syntactic variation in English dialects is of relevance to a range of different 'kinds' of linguists. Grammatical variability has a bearing on the formulation of general principles of human language as well as specific parameters, showing how an 'optimal parametric account depends on particular assumptions about the proper formulation or understanding of the principles of universal grammar' (Kayne, 1996: ix); from a different theoretical perspective, grammatical variation has been incorporated within the framework for mainstream construction grammars (Goldberg, 1995) as arising from choices between coexisting schemata. The notion that variation is crucial to theory has been expressed by sociolinguists and dialectologists for some time. In his discussion of copula deletion, Labov (1969: 737) noted that 'the study of variation adds to our knowledge of linguistic structure'. The articles in this issue show how theoretical modelling can be enriched by taking variation as a core explanandum.

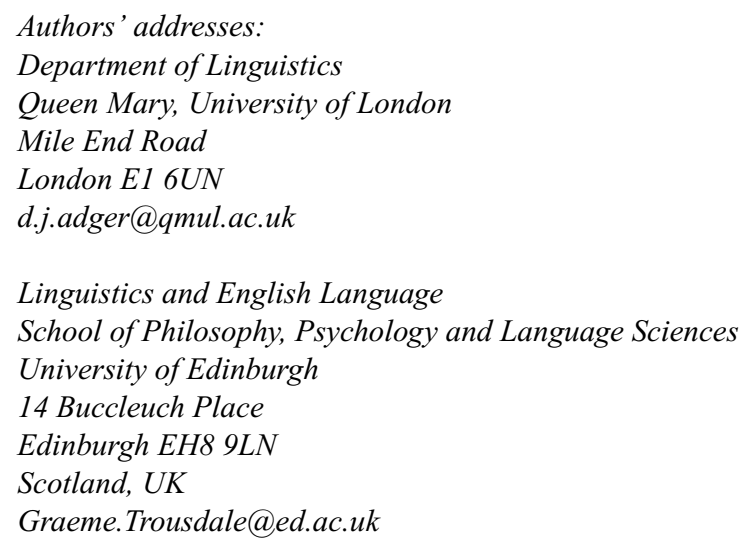

\section{References}

Adger, D. (2006). Combinatorial variability. Journal of Linguistics 42: 503-30.

Adger, D. \& G. Ramchand (2006). Dialect variation in Gaelic relative clauses. In McLeod, W., J. Fraser \& A. Gunderloch (eds.), Cànan is Cultar: Rannsachadh na Gàidhlig 3. Edinburgh: Dunedin Academic Press. 179-92. 
Adger, D. \& J. Smith (2005). Variation and the Minimalist Program. In Cornips, L. \& K. Corrigan (eds.), Syntax and variation: reconciling the biological and the social. Amsterdam: John Benjamins. 149-78.

Adger, D. \& J. Smith (in preparation). Language variation and linguistic theory. Ms. Queen Mary, University of London and University of Glasgow.

Anderwald, L. (2002). Negation in non-standard British English: gaps, regularizations, asymmetries. London: Routledge.

Anttila, A. (1997). Deriving variation from grammar. In Hinskens, F., R. van Hout \& W. L. Wetzels (eds.), Variation, change and phonological theory. Amsterdam: John Benjamins. $36-58$.

Bender, E. (2001). Syntactic variation and linguistic competence. PhD dissertation, Stanford University.

Bhatt, R. (2000). Optimal expressions in Indian English. English Language and Linguistics 4: 69-95.

Black, J. \& V. Motapanyane (eds.) (1996). Microparametric syntax and dialect variation. Amsterdam: John Benjamins.

Borer, H. (1984). Parametric syntax. Dordrecht: Foris.

Bresnan, J. (2000). Explaining morphosyntactic competition. In Baltin, M. \& C. Collins (eds.), The handbook of contemporary syntactic theory. Oxford: Blackwell.

Bybee, J. (2006). From usage to grammar: the mind's response to repetition. Language 86: 711-33.

Carden, G. (1973). Dialect variation and abstract syntax. In Shuy, R. W. (ed.), Some new directions in linguistics. Washington, DC: Georgetown University Press. 1-34.

Casillas-Martinez, L. (2003). The construction-style connection: linking form and meaning in grammar and variation. Unpublished Ms. Stanford University

Chambers, J. K. (2003). Sociolinguistic theory. 2nd edition. Oxford: Blackwell.

Chambers, J. K. \& P. Trudgill (1991). Dialect grammar: data and theory. In Trudgill, P. \& J. K. Chambers (eds.), Dialects of English: studies in grammatical variation. London: Longman. 291-6.

Cheshire, J. (1982). Variation in an English dialect: a sociolinguistic study. Cambridge: Cambridge University Press.

Cheshire, J. (1987). Syntactic variation, the linguistic variable, and sociolinguistic theory. Linguistics 25: 257-82.

Chomsky, N. (1964). Current issues in linguistic theory. The Hague: Mouton.

Chomsky, N. (1986). Knowledge of language. New York: Praeger.

Chomsky, N. (1995). The Minimalist Program. Cambridge, MA: MIT Press.

Clark, L. (2005). A cognitive approach to sociolinguistics. Unpublished MSc dissertation. University of Edinburgh.

Cornips, L. \& K. Corrigan (eds.) (2005). Syntax and variation: reconciling the biological and the social. Amsterdam: John Benjamins.

Croft, W. (2000). Explaining language change: an evolutionary approach. London: Longman.

Goldberg, A. (1995). Constructions: a construction grammar approach to argument structure. Chicago: University of Chicago Press.

Guy, G. (1980). Variation in the group and the individual: the case of final stop deletion. In Labov, W. (ed.), Locating language in time and space. New York: Academic Press. 1-36.

Guy, G. (1991). Explanation in variable phonology: an exponential model of morphological constraints. Language Variation and Change 3: 1-22.

Harris, J. (1984). Syntactic variation and dialect divergence. Journal of Linguistics 20: 303-27.

Henry, A. (1995). Belfast English and Standard English: dialect variation and parameter setting. Oxford: Oxford University Press. 
Hudson, R. A. (1986). Sociolinguistics and the theory of grammar. Linguistics 24: 1053-78.

Hudson, R. A. (1990). English Word Grammar. Oxford: Blackwell.

Hudson, R. A. (1996). Sociolinguistics. 2nd edition. Cambridge: Cambridge University Press.

Hudson, R. A. (1997). Inherent variability and linguistic theory. Cognitive Linguistics $\mathbf{8}$ : 73-108.

Hudson, R. A. (2007). Language networks: the new Word Grammar. Oxford: Oxford University Press.

Ihalainen, O. (1991). On grammatical diffusion in Somerset folk speech. In Trudgill, P. \& J. K. Chambers (eds.), Dialects of English: studies in grammatical variation. London: Longman. 104-19.

Jacobson, S. (1980). Issues in the study of syntactic variation. In Jacobson, S. (ed.), Papers from the Scandinavian Symposium on Syntactic Variation, Stockholm, 18-19 May 1979. Stockholm: Almqvist \& Wiksell. 23-6.

Katz, J. (1981). Language and other abstract objects. Oxford: Blackwell.

Kayne, R. S. (1996). Microparametric syntax: some introductory remarks. In Black, J. \& V. Motapanyane (eds.), Microparametric syntax and dialect variation. Amsterdam: John Benjamins. ix-xviii.

Kerswill, P. (2002). Koineization and accommodation. In Chambers, J. K., P. Trudgill \& N. Schilling-Estes (eds.), The handbook of language variation and change. Oxford: Blackwell. 669-702.

Kimball, J. \& J. Aissen (1971). I think, you think, he think. Linguistic Inquiry 2: 241-6.

King, R. (2005). Morphosyntactic variation and theory: subject-verb agreement in Acadian French. In Cornips, L. \& K. Corrigan (eds.), Syntax and variation: reconciling the biological and the social. Amsterdam: John Benjamins. 198-229.

Kortmann, B. (2002). New prospects for the study of English dialect syntax: impetus from syntactic theory and language typology. In Barbiers, S., L. Cornips \& S. van der Kleij (eds.), Syntactic microvariation. Amsterdam. 185-213. http://www.meertens.nl/books/synmic/

Kortmann, B. (2006). Syntactic variation in English: a global perspective. In Aarts, B. \& A. McMahon (eds.), The handbook of English linguistics. Oxford: Blackwell. 603-24.

Kortmann, B. \& E. Schneider (eds.) in collaboration with K. Burridge, R. Mesthrie \& C. Upton (2004). A handbook of varieties of English. 2 vols. Berlin: Mouton de Gruyter.

Kortmann, B., T. Herrmann, L. Pietsch \& S. Wagner (2005). A comparative grammar of British English dialects: agreement, gender, relative clauses. Berlin: Mouton de Gruyter.

Kretzschmar, W. A. (1999). The future of dialectology. In Upton, C. \& K. Wales (eds.), Dialectal variation in English: proceedings of the Harold Orton Centenary Conference. Leeds: University of Leeds. 271-88.

Kroch, A. (1989). Reflexes of grammar in patterns of language change. Language Variation and Change 1: 199-214.

Kroch, A. (1994). Morphosyntactic variation. Chicago Linguistic Society (CLS) 30 (2): 180-201.

Labov, W. (1966). The social stratification of English in New York City. Washington, DC: Center for Applied Linguistics.

Labov, W. (1969). Contraction, deletion and inherent variability of the English copula. Language 45: 715-62.

Labov, W. (1972). Language in the inner city. Oxford: Blackwell.

Labov, W. (1989). The exact description of the speech community: short $a$ in Philadelphia. In Fasold, R. \& D. Schiffrin (eds.), Language change and variation. Amsterdam: John Benjamins. 1-57.

Langacker, R. (1987). Foundations of Cognitive Grammar, vol. 1: Theoretical perspectives. Stanford: Stanford University Press. 
Langacker, R. (2000). A dynamic usage-based model. In Barlow, M. \& S. Kemmer (eds.), Usage-based models of language. Stanford: CSLI Publications.

Lavandera, B. (1978). Where does the sociolinguistic variable stop? Language in Society 7: $171-82$.

Leino, J. \& J.-K. Östman (2005). Constructions and variability. In Fried, M. \& H. Boas (eds.), Grammatical constructions: back to the roots. Amsterdam: John Benjamins. 191-213.

Meyerhoff, M. (2002). Communities of practice. In Chambers, J. K., P. Trudgill \& N. Schilling-Estes (eds.), The handbook of language variation and change. Oxford: Blackwell. 526-48.

Miller, J. \& R. Cann (1994). Data collection in linguistics. In Asher, R. E. \& J. M. Y. Simpson (eds.), The encyclopedia of language and linguistics. Oxford: Pergamon, 815-17.

Milroy, J. \& L. Milroy (1991). Authority in language: investigating language prescription and standardisation. 2nd edition. London: Routledge.

Milroy, J. \& L. Milroy (eds.) (1993). Real English: the grammar of the dialects of the British Isles. London: Longman.

Milroy, L. (1987). Observing and analysing natural language. Oxford: Blackwell.

Milroy, L. (2002). Social networks. In Chambers, J. K., P. Trudgill \& N. Schilling-Estes (eds.), The handbook of language variation and change. Oxford: Blackwell. 549-72.

Mompean-Gonzalez, J. (2004). Category overlap and neutralization: the importance of speakers' classifications in phonology. Cognitive Linguistics 15: 429-70.

Nagy, N. \& B. Reynolds (1997). Optimality Theory and word-final deletion in Faetar. Language Variation and Change 9: 37-56.

Nevalainen, T. \& H. Raumolin-Brunberg (2003). Historical sociolinguistics. London: Longman.

Orton, H. (1962). Survey of English dialects: introduction. Leeds: Arnold.

Parrott, J. (2006). Bridging the gap: distributed morphological mechanisms of Labovian variation in morphosyntax. Unpublished $\mathrm{PhD}$ dissertation, Georgetown University.

Patrick, P. (2002). The speech community. In Chambers, J. K., P. Trudgill \& N. Schilling-Estes (eds.), The handbook of language variation and change. Oxford: Blackwell. 573-97.

Pesetsky, D. (1998). Some Optimality principles of sentence pronunciation. In Barbosa, P., D. Fox, P. Hagstrom, M. McGinnis \& D. Pesetsky (eds.), Is the best good enough? Cambridge, MA: MIT Press. 337-83.

Pietsch, L. (2005). The grammar of variation: verbal agreement in northern dialects of English. Tübingen: Niemeyer.

Quine, W. O. (1960). Word and object. Cambridge, MA: MIT Press.

Romaine, S. (1982). Socio-historical linguistics: its status and methodology. Cambridge: Cambridge University Press.

Szmrecsanyi, B. (2006). Morphosyntactic persistence in spoken English: a corpus study at the intersection of variationist sociolinguistics, psycholinguistics, and discourse analysis. Berlin: Mouton de Gruyter.

Tagliamonte, S. (1998). Was/were variation across the generations: view from the city of York. Language Variation and Change 10: 153-91.

Tomasello, M. (2000). First steps toward a usage-based theory of language acquisition. Cognitive Linguistics 11: 61-82.

Trousdale, G. (2003a). Modal verbs in Tyneside English: evidence for (socio)linguistic theory. In Facchinetti, R., M. Krug \& F. Palmer (eds.), Modality in contemporary English. Berlin: Mouton de Gruyter. 373-87.

Trousdale, G. (2003b). Simplification and redistribution: an account of modal verb usage in Tyneside English. English World Wide 24: 271-84. 
Upton, C., D. Parry \& J. D. A. Widdowson (1994). Survey of English dialects: the dictionary and grammar. London: Routledge.

Weiner, E. J. \& W. Labov (1983). Constraints on the agentless passive. Journal of Linguistics 19: $29-58$.

Wolfson, N. (1976). Speech events and natural speech: some implications for sociolinguistic methodology. Language in Society 5: 189-209.

Wulff, S., A. Stefanowitsch \& S. Gries (2007) Brutal Brits and persuasive Americans: variety-specific meaning construction in the into-causative. In Radden, G., K-M.

Köpcke, T. Berg \& P. Siemund (eds.), Aspects of meaning construction. Amsterdam: John Benjamins. 265-81. 